\title{
Aggressive Resection of Cervical Desmoid Tumor Invading the Paraspinal Muscles without Recurrence at Eight Year Followup: A Case Report and Review of the Literature
}

\author{
Daniel G Eichberg*, Timur Urakov and Steven Vanni \\ Department of Neurological Surgery, University of Miami Miller School of Medicine, USA
}

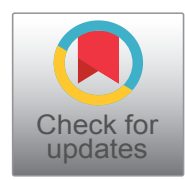

*Corresponding author: Daniel G Eichberg, MD, Neurological Surgery Resident, Department of Neurological Surgery, University of Miami Miller School of Medicine, Lois Pope Life Center, 1095 NW 14th Terrace, Miami, FL 33136, USA, Tel: (301)-873-5357, E-mail: daniel.eichberg@jhsmiami.org

\begin{abstract}
Objective: To provide an overview of head, neck, and spine Desmoid Tumor (DT), to describe the case of a patient who underwent aggressive surgical resection of a large invasive cervical DT, and to analyze the DT literature. We discuss the importance of aggressive surgical margins in decreasing recurrence risk in head, neck, and spine DTs.

Methods: A twenty-three-year-old female patient with history of a left cervical neurofibroma resection presented two years later with neck mass regrowth. The mass was aggressively resected, and occiput to T1 fusion was performed. Additionally, the head, neck, and spine DT literature was reviewed regarding surgical margin status and recurrence rate. A "N-1" Chi-squared test was used to compare proportions, between percentage of patients that experienced recurrence after gross total resection, and percentage of patients that experienced recurrence after subtotal resection, to determine statistical significance $(p<0.05)$.
\end{abstract}

Results: Histologically, the lesion was shown to be a DT, with posterior paracervical spinal musculature invasion. The surgery was well tolerated with no complications. At eight years postoperative followup, the patient is doing well with no tumor recurrence. Nine studies were identified describing surgical margin status and recurrence rate of head, neck, and spine DT. When recurrence rates were compared in patients with grossly negative surgical margins and grossly positive surgical margins for head, neck, and spine DTs, two studies showed statistical significance $(p<$ 0.05 ) for lower recurrence rate after gross total resection, and seven showed a trend toward lower recurrence rates in patients with gross total resection.

Conclusion: DTs are difficult clinical entities to cure due to high recurrence rate after resection. Consistent with previous studies indicating that aggressive surgical margins are associated with a decreased risk of recurrence, we present a case report of a female patient who underwent aggressive resection of a large DT and remains tumor-free after eight years. Thus, we recommend aggressive surgical resection of head, neck, and spine DTs to minimize recurrence risk.

\section{Keywords}

Aggressive fibromatosis, Aggressive resection, Desmoid tumor, Head and neck, Recurrence, Spine

\begin{abstract}
Abbreviations
A: Anterior; APC: Adenomatous Polyposis Coli; BMP: Bone Morphogenic Protein; cm: centimeter; DT: Desmoid Tumor; FAP: Familial Adenomatous Polyposis; mm: millimeter; NSAID: Non-Steroidal Anti-Inflammatory Drug; pt: patients; S: Superior
\end{abstract}

\section{Introduction}

Desmoid Tumors (DTs), also known as aggressive fibromatosis, are benign, fast growing, and locally invasive fibroblastic neoplasms which arise from mesenchymal stem cells [1]. While DTs do not spread metastatically, they can invade local tissue and frequently recur after surgical resection [2-4]; for this reason they are often categorized with low-grade soft tissue sarcomas [5]. Approximately 2-4 cases of DTs per million people occur each year, and account for $0.03 \%$ of all neoplasms [6] and $3 \%$ of soft tissue tumors [7]. DTs have been reported to occur in nearly every bodily location, with an estimated $7 \%$ to $15 \%$ of DTs occurring in the head and neck $[8,9]$. 
Although most cases of DTs are sporadic [3], there is a distinct association with Familial Adenomatous Polyposis (FAP, Gardner's syndrome) and other Adenomatous Polyposis Coli (APC) gene mutations [10]. In fact, patients with FAP have DTs at approximately 850 times the rate of the general population, most commonly located in the small intestine or mesentery [11]. Development of DTs is thought to be associated with female sex hormones, as the tumors occur more commonly in females, their growth rate is directly related to endogenous estrogen levels in female patients, and estradiol receptors have been found to be present in the tumor cytosol [12]. Indeed, tumor regression has been reported with the use of the antiestrogen compound tamoxifen $[5,13,14]$. Interestingly, in a study reviewing the use of endocrine therapy for desmoid tumors, Wilcken and Tattersall (1991) found that of 23 patients with DTs treated with tamoxifen responded to the therapy
[14]. Additionally, a history of prior surgery or trauma at the site of the DT is often found [15].

Presently, the standard of care for DTs is surgical resection with wide margins [4]. Although the post-surgical recurrence rate is high, with up to $72 \%$ of patients experiencing recurrence, surgical resection with wide or aggressive margins has been shown to reduce the recurrent rate [16]. Several studies suggest that cases in which wide or aggressive margins cannot be achieved, adjuvant radiotherapy may decrease recurrence rates $[9,17,18]$. Medical therapy, including NSAIDs, tamoxifen, and chemotherapy, remains controversial [11].

Here, we present the eight year followup of the case of a patient who underwent aggressive surgical resection of cervical DT with occiput to thoracic fusion. We focus on the importance of instrumentation due to aggressive resection of posterior paraspinal musculature

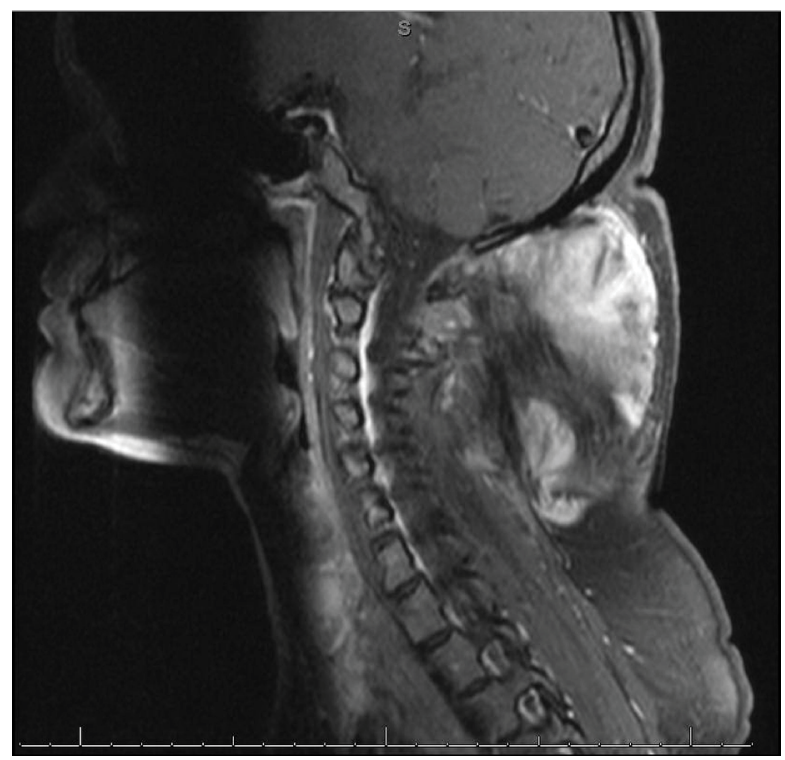

A

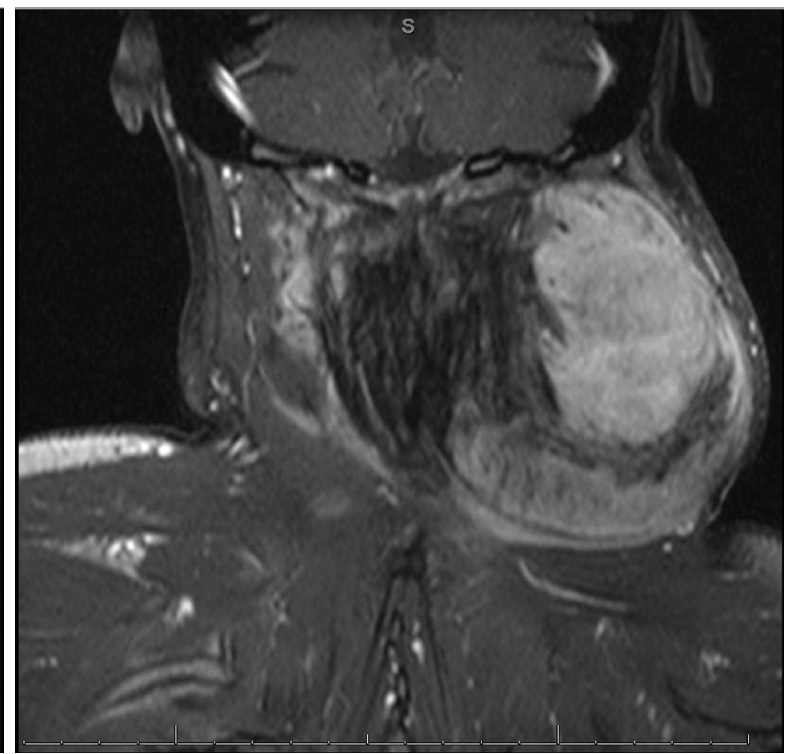

B

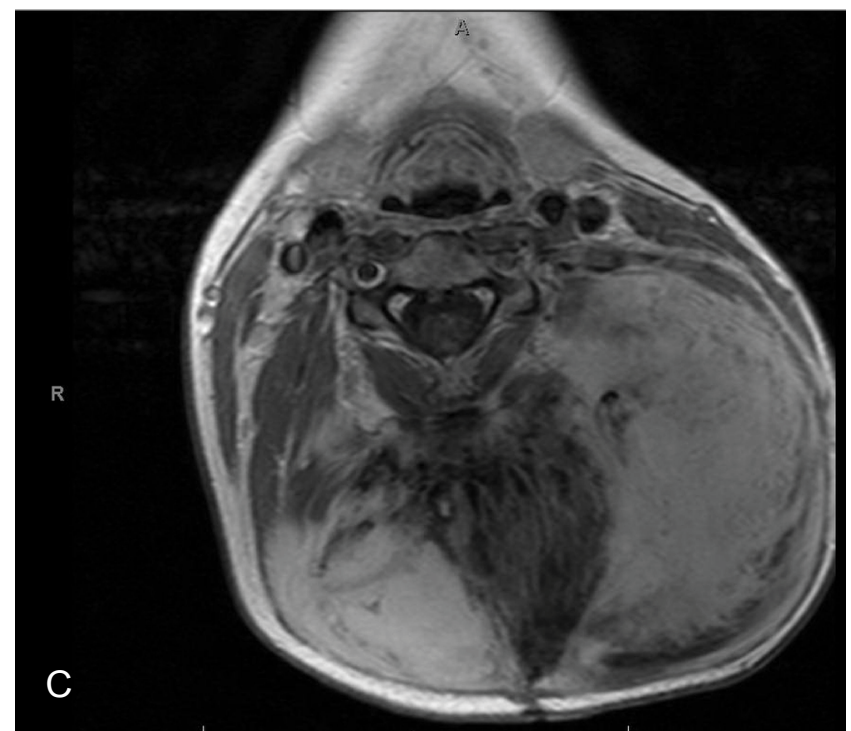

Figure 1: Preoperative magnetic resonance image of neck. A large desmoid tumor invading the left cervical paraspinal muscles is seen. Panel A) sagittal T1 weighted image fast spin echo fat saturated flow compensated with gadolinium; Panel B) Axial T1 weighted image fast spin echo with gadolinium. Diameter $A$ is $132.1 \mathrm{~mm}$ and diameter $B$ is $83.1 \mathrm{~mm}$; Panel C) Coronal T1 weighted image spin echo fat saturated flow with gadolinium enhancement.

Abbreviations: S: Superior; A: Anterior. 
[19]. Now, at eight years followup, we demonstrate that the patient is recurrence-free.

We also present a discussion of the literature regarding the association of head, neck, and spine DT resection margin status and recurrence rate.

\section{Methods}

\section{Case report}

The patient was a 25 -year-old female with partial resection and biopsy of a left cervical neurofibroma extending from the sternocleidomastoid posteriorly and posterior triangle of the neck, two years prior to presentation. Over time, the mass appeared to recur and enlarge, causing severe deformity of the posterior aspect of the patient's skull and neck and compromising the soft tissue structures of the neck (Figure 1). After obtaining consent for surgery, the patient was fiber optically intubated due to compression of the airway. A Mayfield head holder was affixed to the skull. She was turned prone onto a Jackson table. All contact points were doubly padded. Her arms were kept down to her side. She was prepped from the portion of the skull all the way down to the buttocks in case of the need for a very large latissimus dorsi flap to be elevated. She was prepped and draped in the usual sterile fashion. The intraoperative computerized tomography unit was used for intraoperative neuronavigation.

AY-type of incision utilizing the previous incision from the base of the occiput down to the midline to approximately $\mathrm{T} 1$ was made. Then, a sharp dissection over the mass of the tumor away from the surrounding soft tissue was performed.

The base of the mass was found to be intimately attached to the occiput and the C1-C2 vertebra, so a Cavitron ultrasonic aspirator was used to core it out internally. However, the mass was too hard so this could not be accomplished. Loop cautery was then used to start cutting off pieces of the tumor. Again, it was so hard it broke the loop. A Bovie at its highest setting was then utilized to cut pieces of the tumor away slice by slice, eventually debulking the tumor significantly.
After the occiput was identified, a periosteal was used to scrape the tumor from the bone. The tumor appeared to emerge from a portion of the left $\mathrm{C} 2$ ganglion, and it was separated from the lamina, especially at the occiput and $\mathrm{C} 1$ junction and at the junction of the mastoid process to prevent inadvertent tearing of the vertebral arteries.

All muscle which appeared abnormal was removed, and the entire mass was eventually resected. Apparent residual tumor was not seen in any other locations.

Because of the extensive tumor invasion of the posterior paraspinal muscles requiring resection of all posterior cervical muscles from the occiput to $\mathrm{C6}-\mathrm{C} 7$, an occiput to T1 fusion was required. An occipital plate with a 10-millimeter screws bolting it to the occiput were placed, followed by screws in the lateral masses of $\mathrm{C} 2$, $\mathrm{C} 3, \mathrm{C} 4, \mathrm{C} 5$, and $\mathrm{C} 6$, and then pedicle screws at $\mathrm{T} 1$ were placed, all with neuronavigational aide. After all the screws were placed, a rod was then bent into position and cut. All facet complexes were decorticated and then the wound was pulse lavaged.

Given the fact that all the muscle posteriorly was removed from the base of the occiput down to about C6$\mathrm{C7}$, a portion of the trapezius muscle was elevated. This flap was swung superiorly up bilaterally to layer over the hardware. A piece of allograft from the iliac crest was cut and then fashioned to fit from the occiput at the $\mathrm{C} 2$, putting a Songer cable down to lock it into position and then packing all the facet complexes with allograft and bone morphogenic protein.

\section{Literature review}

A comprehensive retrospective review of the literature was performed using the key words "desmoid tumor", "desmoid-type fibromatosis", and "aggressive fibromatosis", alone or together to search PubMed, PubMed, Ovid Medline, Ovid EMBASE, Scopus, and Web of Science database and all neurosurgical journals. Positive inclusion criteria included desmoid tumors of the head, neck, and spine, treated with surgery, as well as reporting of surgical margin status and completeness of excision.

Table 1: Recurrence rates of head and neck desmoid tumors after complete and incomplete excisions.

\begin{tabular}{|c|c|c|c|c|c|c|}
\hline Study & $\begin{array}{l}\text { Mean } \\
\text { Followup } \\
\text { (years) }\end{array}$ & $\begin{array}{l}\text { Grossly } \\
\text { complete } \\
\text { resection (\# pts) }\end{array}$ & $\begin{array}{l}\text { Recurrence rate } \\
\text { after complete } \\
\text { resection (\%) }\end{array}$ & $\begin{array}{l}\text { Grossly } \\
\text { incomplete } \\
\text { resection (\# pts) }\end{array}$ & $\begin{array}{l}\text { Recurrence rate } \\
\text { after incomplete } \\
\text { resection (\%) }\end{array}$ & P-value ${ }^{*}$ \\
\hline Alherabi, et al. (2015) [27] & 1.3 & 0 & $\mathrm{n} / \mathrm{a}$ & 1 & $100 \%$ & $\mathrm{n} / \mathrm{a}$ \\
\hline Cohen, et al. (2008) [28] & 2 & 1 & $0 \%$ & 0 & $\mathrm{n} / \mathrm{a}$ & $\mathrm{n} / \mathrm{a}$ \\
\hline Conley, et al. (1966) [22] & 9 & 15 & $40 \%$ & 21 & $52 \%$ & $p=0.47$ \\
\hline de Vloo, et al. (2015) [3] & 2.3 & 25 & $16 \%$ & 9 & $22 \%$ & $p=0.67$ \\
\hline Fasching, et al. (1988) [23] & 5.8 & 32 & $25 \%$ & 14 & $86 \%$ & $p=0.00014$ \\
\hline Hoos, et al. (2000) [24] & 4.5 & 18 & $6 \%$ & 3 & $33 \%$ & $p=0.13$ \\
\hline Koukoutsis, et al. (2009) [29] & 0.5 & 1 & $0 \%$ & 0 & $\mathrm{n} / \mathrm{a}$ & $\mathrm{n} / \mathrm{a}$ \\
\hline Miyashita, et al. (2016) [30] & 4.4 & 16 & $6.3 \%$ & 29 & $50 \%$ & $p=0.0035$ \\
\hline Wang, et al. (2006) [26] & 5.4 & 20 & $15 \%$ & 4 & $25 \%$ & $p=0.624$ \\
\hline
\end{tabular}

"P-value for difference in recurrence rate between patients with grossly complete and grossly incomplete resection.

Abbreviations: pt: patients. 


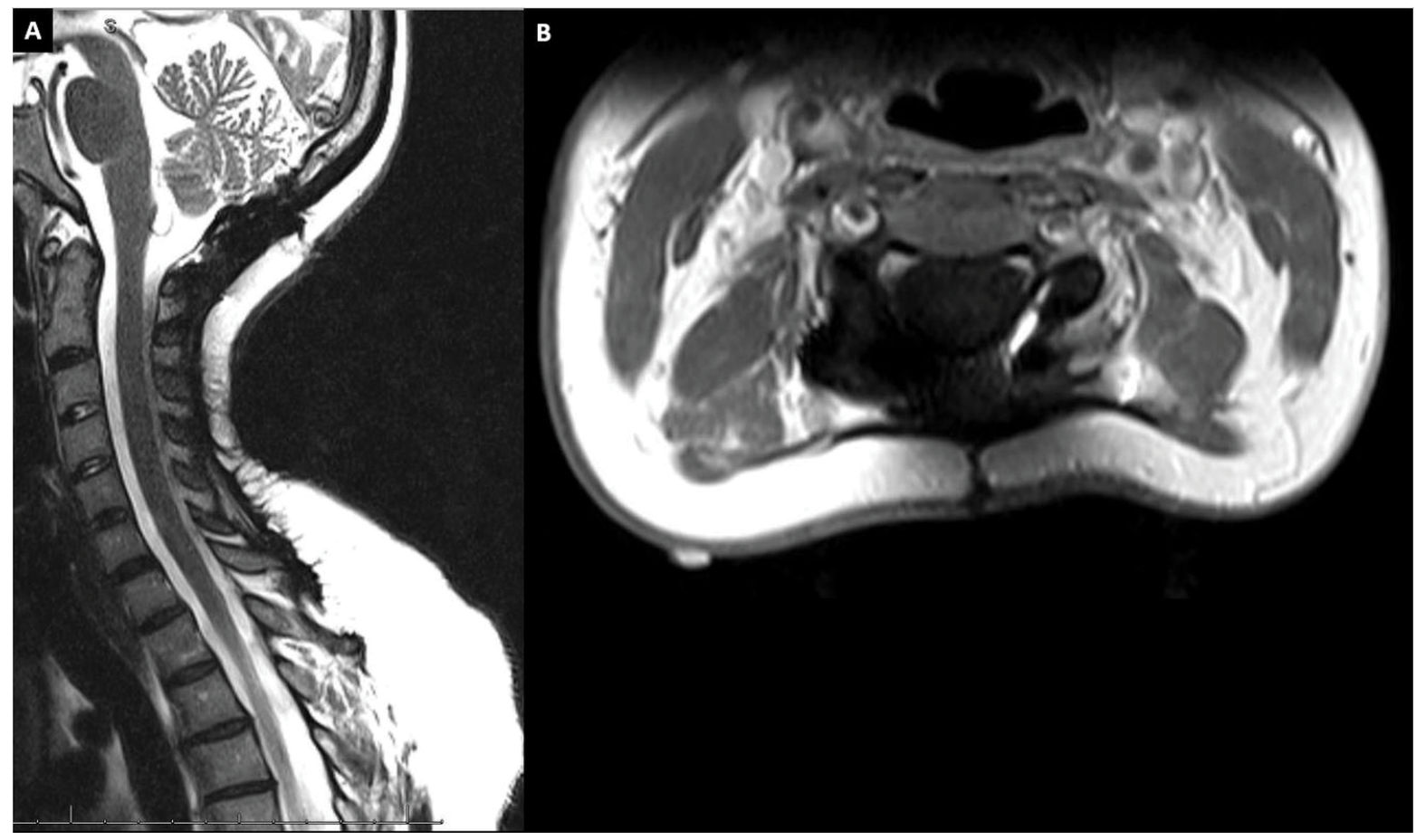

Figure 2: Postoperative magnetic resonance image cervical spine at eight year followup. No tumor recurrence is observed. Panel A) Sagittal T2 weighted MRI image; B) Axial T1 weighted fast spin echo with gadolinium MRI image.

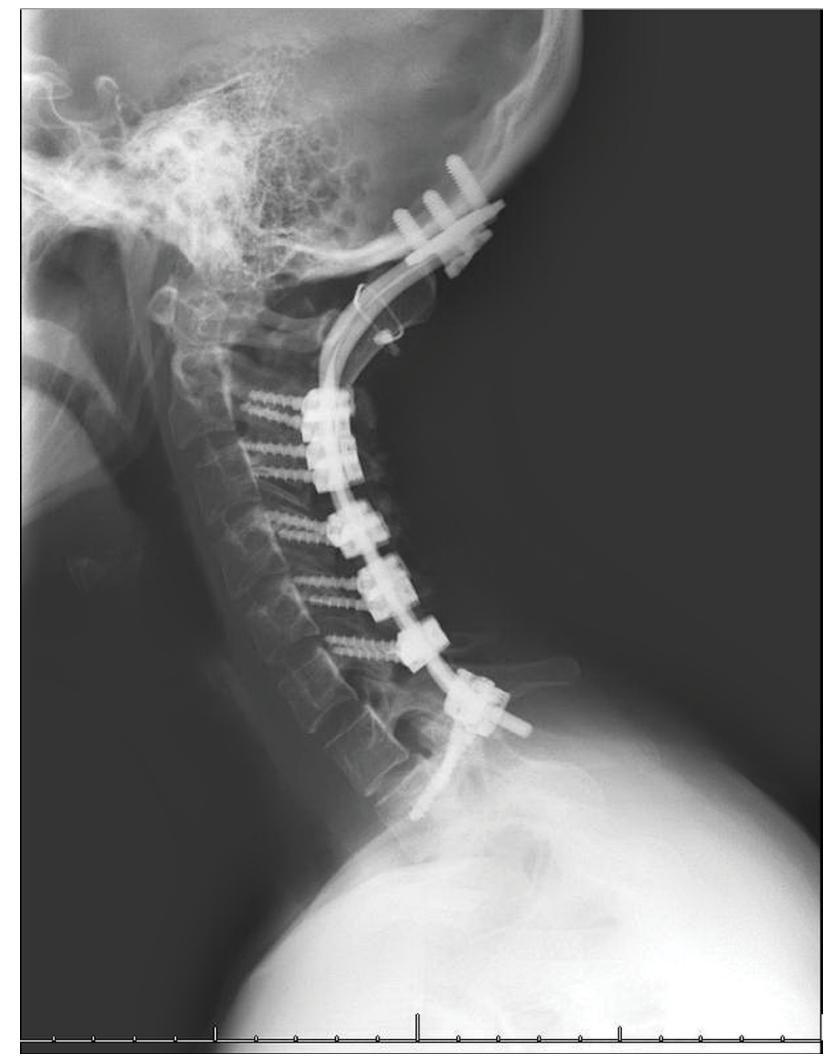

Figure 3: Lateral cervical spine plan x-ray at eight years followup. Instrumentation for occiput to T1 fusion is demonstrated.

\section{Statistical analysis}

A "N-1" Chi-squared test was performed to determine whether there was a statistically significant difference in DT recurrence rates between patients with grossly complete resections and grossly incomplete resections, as is recommended by Campbell and Rich- ardson [20,21]. Statistical significance was defined as a $\mathrm{p}$-value less than 0.05 . Sample size for each study is detailed in Table 1.

\section{Results}

\section{Case report}

Histologically, the lesion was shown to be a desmoid tumor, with invasion of the posterior paracervical spinal musculature. The patient tolerated the surgery well with no complications. No further adjuvant radiation treatment was offered. At eight years postoperative followup, the patient is doing well with no tumor recurrence (Figure 2 and Figure 3), and delivered a healthy baby.

\section{Literature review}

Nine studies were identified describing surgical margin status and recurrence rate of head, neck, and spine DT. When recurrence rates were compared in patients with grossly negative surgical margins and grossly positive surgical margins for head, neck, and spine DTs, two studies showed statistical significance $(p<0.05)$ for lower recurrence rate after gross total resection, and seven showed a trend toward lower recurrence rates in patients with gross total resection. A summary of the recurrence rates following grossly complete resections compared to grossly incomplete excisions in case series with DTs of the head and neck is presented [3,22-30] (Table 1).

\section{Discussion}

Desmoid Tumors (DTs), also known as aggressive fibromatosis, are fibroblastic neoplasms which can arise in almost all parts of the body [1]. Although they are benign lesions and thus do not spread metastatically, DTs are fast 
growing, locally invasive, and recur after surgical resection at high rates [2-4]. While DTs at all sites commonly recur after surgical excision, recurrence rates with head and neck DTs are much higher. One study showed that recurrences occurred in $70 \%$ of patients with head and neck DTs, but only $50 \%$ of DTs at other locations [8]. This could be partially explained by proximity to, or involvement of, eloquent anatomical locations and hesitation in aggressive attainment of negative margins.

We present the case of a patient who underwent aggressive surgical resection of cervical DT with occiput to thoracic fusion. Instrumentation was necessitated by aggressive resection of posterior paraspinal musculature. Presently, at eight years followup, we demonstrate that the patient remains free of recurrence.

A paucity of data exists pertaining to treatment strategies focused on reducing DT recurrence rates beyond case reports and limited case series. However, the little evidence available does support aggressive resection of tumor with negative margins. One retrospective analysis of the literature collected for desmoid tumors in all locations found that local control rates for DTs with positive surgical margins were $41 \%$, compared with local control rates of $72 \%$ for DTs with negative surgical margins (mean followup time 10.4 years) [18]. Similarly, another retrospective analysis of the literature collected for extra-abdominal DTs found that $72 \%$ of patients with a marginal or intralesional excision according to the Enneking classification system had a recurrence, compared with only $27 \%$ of patients who had wide or aggressive microscopic surgical margins [16].

Studies focusing on DTs of the head, neck, and spine further support the assertion that complete tumor resection with negative margins improve the chances of recurrence-free survival [22-26] (Table 1). These studies show either statistical significance or a trend toward lower recurrence rates in patients with aggressive surgical margins for head, neck, and spine DTs compared to patients with positive surgical margins. While aggressive surgical resection may be limited by cosmesis or involvement of critical neurovascular structures, the decision for such aggressive resection could potentially be supported by the improved rate of recurrence.

Although the authors did not analyze head and neck DTs separately, Mullen, et al. found that fewer than half of patients with DTs from all body sites that underwent surgery with positive margins experienced recurrence, although they do advocate for wide excision with negative margins without compromising function [31]. In contrast, Wang, et al. found that negative surgical margins and absence of tumor invasion into major nerves and blood vessels were associated with low recurrence rates [32]. Although DTs do exhibit a tendency to recur in scar tissue, Garvey, et al. found that postoperative DT recurrence rates in both primary closures as well as complex reconstructions were similar, leading them to recommend against limiting the magnitude reconstruction magnitude to reduce recurrence rates [33].

Use of radiation therapy in the treatment of DTs is controversial, as DTs are benign lesions, and radiation therapy carries a risk of adverse side effects such as fibrosis, cellulitis, neurological deficits, and secondary malignant transformation. One large retrospective study comparing the results of surgery and/or radiation therapy at all anatomic locations found that in cases of surgical resections with negative margins, the recurrence rate was not statistically significantly different between surgery alone and surgery with postoperative radiation therapy [18]. However, in cases of surgical resection with positive margins, postoperative radiation therapy improved local disease control from $46 \%$ to $78 \%(p=0.0001)[18]$. These results suggest that radiation therapy should not be given when aggressive surgical resection with negative margins is possible, but it may be indicated when only an incomplete surgical resection with positive margins is achievable.

Medical therapy for the treatment of DT, such as NSAIDs (including Sulindac) and tamoxifen, have been utilized with mixed results in patients with inoperable tumors or who are not surgical candidates [34]. However, pharmacologic treatment of head, neck, and spine DTs has only been used infrequently, so robust data regarding its efficacy is lacking $[7,34,35]$. Although NSAID therapy has relatively low morbidity, there is currently no prospective randomize data to demonstrate that NSAIDs alone are efficacious for the treatment of DTs [36].

Use of Bone Morphogenic Protein (BMP) is generally cautioned in cases with history of neoplasms. A retrospective study in 2013 described increased risk of benign tumors associated with BMP use in spinal fusion surgeries. In the study, the BMP-exposed group had a significantly higher incidence of benign tumors of the uterus ( $2.6 \%$ vs. $1.7 \% ; P=0.002)$, nervous system $(0.81 \%$ vs. $0.31 \% ; P<0.001)$, and unspecified sites (0.38\% vs. $0.14 \% ; P=0.009$ ) [37]. Further reports evaluating cancer risks in BMP use have not observed the correlation, leaving the issue unresolved $[38,39]$. No current evidence exists on use of BMP in patients with desmoid tumors. The surgery described in our case report was performed in 2008. Intraoperative pathology showed no malignant cells. With evidence available at the time, we felt it was safe to use bone morphogenic protein to spare the patient a secondary incision into the iliac crest. On follow up, there is no evidence of any recurrence or new tumor formation as of June of 2016.

\section{Conclusion}

Although they are benign lesions with no metastatic potential, Desmoid Tumors (DTs) are locally invasive and fast growing. They have a high incidence of recurrence after surgical resection, with head and neck DTs exhibiting among the highest rate of recurrence and are thus difficult to definitively cure. We have provid- 
ed an analysis of the literature showing that wide or aggressive surgical resection of DTs is associated with a decreased rate of tumor recurrence. We have also provided a case report of a patient who underwent an aggressive resection of a DT of the cervical paraspinal muscles and remains disease free at eight-year follow up, leads a normal life and has delivered a baby. Thus, we advocate for the aggressive resection of surrounding soft tissue with negative margins during head and neck DT surgeries and supplementation with instrumentation as needed.

\section{Disclosures}

The authors report no conflict of interest concerning the materials or methods used in this study or the findings specified in this paper.

\section{Acknowledgements}

We have no acknowledgments to declare.

\section{References}

1. Wu C, Amini-Nik $S$, Nadesan $P$, Stanford WL, Alman BA (2010) Aggressive fibromatosis (desmoid tumor) is derived from mesenchymal progenitor cells. Cancer Res 70: 76907698.

2. Escobar C, Munker R, Thomas JO, Li BD, Burton GV (2012) Update on desmoid tumors. Ann Oncol 23: 562-569.

3. De Vloo P, De Vlieger J, Vander Poorten V, Sciot R, van Loon J, et al. (2015) Desmoid tumors in neurosurgery: a review of the literature. Clin Neurol Neurosurg 129: 78-84.

4. Shakur SF, Takagi I, Jacobsohn JA, Golden BM, Karahalios DG (2013) Spinal fibromatosis: A report of two cases and review of the literature. Spine J 13: e1-e6.

5. de Bree E, Keus R, Melissas J, Tsiftsis D, van Coevorden F (2009) Desmoid tumors: need for an individualized approach. Expert Rev Anticancer Ther 9: 525-535.

6. Reitamo JJ, Hayry P, Nykyri E, Saxen E (1982) The desmoid tumor. I. Incidence, sex-, age- and anatomical distribution in the Finnish population. Am J Clin Pathol 77: 665-673.

7. de Bree E, Zoras O, Hunt JL, Takes RP, Suarez C, et al. (2014) Desmoid tumors of the head and neck: a therapeutic challenge. Head Neck 36: 1517-1526.

8. Masson JK, Soule EH (1966) Desmoid tumors of the head and neck. Am J Surg 112: 615-622.

9. Baumert BG, Spahr MO, Von Hochstetter A, Beauvois S, Landmann C, et al. (2007) The impact of radiotherapy in the treatment of desmoid tumours. An international survey of 110 patients. A study of the Rare Cancer Network. Radiat Oncol 2: 12.

10. De Wever I, Dal Cin P, Fletcher CD, Mandahl N, Mertens F, et al. (2000) Cytogenetic, clinical, and morphologic correlations in 78 cases of fibromatosis: a report from the CHAMP Study Group. CHromosomes And Morphology. Mod Pathol 13: $1080-1085$.

11. Laufer I, Wolinsky JP, Gokaslan ZL (2013) Desmoid tumors. World Neurosurg 79: 97-98.

12. Hayry P, Reitamo JJ, Totterman S, Hopfner-Hallikainen D, Sivula A (1982) The desmoid tumor. II. Analysis of factors possibly contributing to the etiology and growth behavior. Am J Clin Pathol 77: 674-680.
13. Reitamo JJ, Scheinin TM, Hayry P (1986) The desmoid syndrome. New aspects in the cause, pathogenesis and treatment of the desmoid tumor. Am J Surg 151: 230-237.

14. Wilcken N, Tattersall MH (1991) Endocrine therapy for desmoid tumors. Cancer 68: 1384-1388.

15. Nieuwenhuis MH, Lefevre JH, Bülow S, Järvinen H, Bertario L, et al. (2011) Family history, surgery, and APC mutation are risk factors for desmoid tumors in familial adenomatous polyposis: an international cohort study. Dis Colon Rectum 54: $1229-1234$.

16. Leithner A, Gapp M, Leithner K, Radl R, Krippl P, et al. (2004) Margins in extra-abdominal desmoid tumors: a comparative analysis. J Surg Oncol 86: 152-156.

17. Jelinek JA, Stelzer KJ, Conrad E, Bruckner J, Kliot M, et al. (2001) The efficacy of radiotherapy as postoperative treatment for desmoid tumors. Int J Radiat Oncol Biol Phys 50: 121-125.

18. Nuyttens JJ, Rust PF, Thomas CR, Turrisi AT (2000) Surgery versus radiation therapy for patients with aggressive fibromatosis or desmoid tumors: A comparative review of 22 articles. Cancer 88: 1517-1523.

19. Hood B, Benglis DM, Levi AD, Vanni S (2013) Occiput to thoracic fusion after surgical resection of desmoid tumor. World Neurosurg 79: 207.e15-207.e18.

20. Campbell I (2007) Chi-squared and Fisher-Irwin tests of two-by-two tables with small sample recommendations. Stat Med 26: 3661-3675.

21. Richardson JT (2011) The analysis of $2 \times 2$ contingency tables--yet again. Stat Med 30: 890.

22. Conley J, Healey WV, Stout AP (1966) Fibromatosis of the head and neck. Am J Surg 112: 609-614.

23. Fasching MC, Saleh J, Woods JE (1988) Desmoid tumors of the head and neck. Am J Surg 156: 327-331.

24. Hoos A, Lewis JJ, Urist MJ, Shaha AR, Hawkins WG, et al. (2000) Desmoid tumors of the head and neck--a clinical study of a rare entity. Head Neck 22: 814-821.

25. Sharma A, Ngan BY, Sándor GK, Campisi P, Forte $V$ (2008) Pediatric aggressive fibromatosis of the head and neck: a 20-year retrospective review. J Pediatr Surg 43: 1596-1604.

26. Wang CP, Chang YL, Ko JY, Cheng $\mathrm{CH}$, Yeh CF, et al. (2006) Desmoid tumor of the head and neck. Head Neck 28: 1008-1013.

27. Alherabi AZ, Marglani OA, Bukhari DH, Al-Khatib TA (2015) Desmoid tumor (fibromatosis) of the head and neck. Saudi Med J 36: 101-103.

28. Cohen S, Ad-El D, Benjaminov O, Gutman H (2008) Post-traumatic soft tissue tumors: case report and review of the literature a propos a post-traumatic paraspinal desmoid tumor. World J Surg Oncol 6: 28.

29. Koukoutsis I, Pappas A, Karanikas G, Kotzadimitriou K, Chrysikos J, et al. (2009) Desmoid tumor of the supraclavicular region: a case report. Cases J 2: 7222.

30. Miyashita H, Asoda S, Soma T, Munakata K, Yazawa M, et al. (2016) Desmoid-type fibromatosis of the head and neck in children: a case report and review of the literature. J Med Case Rep 10: 173.

31. Mullen JT, Delaney TF, Kobayashi WK, Szymonifka J, Yeap BY, et al. (2012) Desmoid tumor: analysis of prognostic factors and outcomes in a surgical series. Ann Surg Oncol 19: 4028-4035. 
32. Wang YF, Guo W, Sun KK, Yang RL, Tang XD, et al. (2015) Postoperative recurrence of desmoid tumors: clinical and pathological perspectives. World J Surg Oncol 13: 26.

33. Garvey PB, Booth JH, Baumann DP, Calhoun KA, Liu J, et al. (2013) Complex reconstruction of desmoid tumor resections does not increase desmoid tumor recurrence. $\mathrm{J} \mathrm{Am}$ Coll Surg 217: 472-480.

34. Janinis J, Patriki M, Vini L, Aravantinos G, Whelan JS (2003) The pharmacological treatment of aggressive fibromatosis: a systematic review. Ann Oncol 14: 181-190.

35. Garbay D, Le Cesne A, Penel N, Chevreau C, Marec-Berard $P$, et al. (2012) Chemotherapy in patients with desmoid tumors: a study from the French Sarcoma Group (FSG). Ann Oncol 23: 182-186.
36. Collins BJ, Fischer AC, Tufaro AP (2005) Desmoid tumors of the head and neck: A review. Ann Plast Surg 54: 103108.

37. Lad SP, Bagley JH, Karikari IO, Babu R, Ugiliweneza B, et al. (2013) Cancer after spinal fusion: the role of bone morphogenetic protein. Neurosurgery 73: 440-449.

38. Kelly MP, Savage JW, Bentzen SM, Hsu WK, Ellison SA, et al. (2014) Cancer risk from bone morphogenetic protein exposure in spinal arthrodesis. J Bone Joint Surg Am 96: 1417-1422.

39. Malham GM, Giles GG, Milne RL, Blecher CM, Brazenor GA (2015) Bone Morphogenetic Proteins in Spinal Surgery: What Is the Fusion Rate and Do They Cause Cancer? Spine (Phila Pa 1976) 40: 1737-1742. 